Article

\title{
Occurrence of Campylobacter spp. in Selected Small Scale Commercial Broiler Farms of Bangladesh Related to Good Farm Practices
}

\author{
Badrul Alam ${ }^{1}$, Md. Nasir Uddin ${ }^{1}{ }^{(}$, Debashish Mridha ${ }^{1}$, A. H. M. Taslima Akhter ${ }^{2}$, \\ SK Shaheenur Islam ${ }^{3} \mathbb{D}$, A. K. M. Ziaul Haque ${ }^{1}$ and S. M. Lutful Kabir ${ }^{1, * \mathbb{D}}$ \\ 1 Department of Microbiology and Hygiene, Bangladesh Agricultural University, Mymensingh 2202, \\ Bangladesh; badrul.alamjstu@gmail.com (B.A.); nasirmbsobug@gmail.com (M.N.U.); \\ debashish.dip20@gmail.com (D.M.); vetzia.2004.bd@gmail.com (A.K.M.Z.H.) \\ 2 FAO-Food Safety Program (FSP), Institute of Public Health, Mohakhali, Dhaka 1215, Bangladesh; \\ takhter36@yahoo.com \\ 3 Department of Livestock Services, Krishi Khamar Sarak, Farmgate, Dhaka 1215, Bangladesh; \\ s_islam73@live.com \\ * Correspondence: lkabir79@bau.edu.bd; Tel.: +88-091-67401-6 (ext. 63218)
}

Received: 6 October 2020; Accepted: 10 November 2020; Published: 13 November 2020

\begin{abstract}
Poultry origin Campylobacter is considered as one of the leading causal agents of human foodborne illness. This study was conducted to estimate the occurrence, molecular identification, and antimicrobial resistance (AMR) of Campylobacter species from the broiler farms in Bangladesh. Samples (352) were collected from 32 farms and comprised of 128 cloacal swab, 64 feed, 64 drinking water, 64 attendants' hand rinsed water, and 32 whole carcasses. All samples were tested for the presence of Campylobacter via cultural, biochemical, and PCR. The AMR was determined via the disc diffusion method. An overall occurrence of Campylobacter spp. was estimated as $26.4 \%$. The level of Campylobacter contamination was found to be higher in conventional farms $(36.4 \%)$ than the good practice farms $(16.5 \%)$ including all sample categories $(p=0.000)$. Of 93 isolates, $67.74 \%$ and $32.26 \%$ were confirmed as $C$. jejuni and C. coli respectively, of which $34.92 \%$ C. jejuni, and 30\% C. coli were shown to be multidrug-resistant. A significant occurrence of Campylobacter contamination in broiler farms with multidrug resistant patterns might be cogitated as serious food safety and public health concern linking to poultry food chain. A risk reduction approach through good farming practices targeting the prudent use of antimicrobials for broiler production is thus necessitated.
\end{abstract}

Keywords: Campylobacter spp.; occurrence; broiler farms; molecular detection; multidrug resistant; Bangladesh

\section{Introduction}

Campylobacter spp. are food-borne pathogens which are microaerophilic, spiral, or slightly curved, motile, non-spore forming Gram-negative bacteria having a single flagellum at one or both poles [1]. The thermophilic Campylobacter is well documented in poultry mostly in broilers and turkeys [2]. However, this organism is infrequently identified in commercial broiler flocks under the age of 2-3 weeks [3]. Campylobacter is recognized as one of the leading causal agents of foodborne gastroenteritis in humans. Every year a large number of people are affected by this pathogen globally [4]. A total of 246,307 human cases were confirmed as Campylobacter infection by the European Food Safety Authority (EFSA) as the highest occurrence for any bacterial pathogen in Europe, of which C. jejuni and C. coli were accountable as $83.6 \%$ and $8.5 \%$ respectively [5]. 
Among the Campylobacter spp., C. jejuni, C. coli, and C. lari can transmit from the intestinal tract of animals and may be contaminated animal origin foods. Amongst the species of Campylobacter, C. jejuni and C. coli are regarded to be a major contributor (around 90\%) of human campylobacteriosis [6]. Since these species of Campylobacter were documented as causal agents of human diarrheal disease, their presence in food indicate a potential health hazard. Apart from the enteric diseases, Campylobacter infection can cause Guillain-Barré syndrome (GBS), with severe chronic symptoms following the infection, and characterized by acute paralysis resulting from an autoimmune and slow healing rate [7]. In poultry supply chain, the main phases of contamination namely farm response, transport, slaughtering, and meat processing in the live bird markets (LBMs) and consumption. These pathogens can remain viable along the food chains with high accumulation at the consumer level [8].

Amongst the Campylobacter isolates, C. jejuni (51\%) and C. coli (35.5\%) are the more prevalent species in broiler meat [9] and transmission occurs due to the improper cleaning and disinfection of equipment and poultry crates [10]. Since various antimicrobial supplementations in poultry feed have linked with the development of AMR bacteria present in carcass and chicken meat products is now a paramount public health concern [11-13]. This practice has a high impact on food safety both in veterinary and human health, and considered to be devastating more rapidly in low- and middle- income countries (LMICs), where the imprudent use of antibiotics is more common to intensify livestock productivity [14]. Strict biosecurity measurement through the adoption good agriculture practices (GAP) in poultry farming could minimize the risk of introduction and later subsistence of these pathogens in commercial poultry flocks $[15,16]$.

In Bangladesh, the major proportion (50-60\%) of poultry meat comes from sector three small scale poultry production system, where a low to minimum level of biosecurity is being maintained at the rural settings [17], that facilitates to increase likelihood of Campylobacter spp. colonization in poultry. A significant number of studies have been conducted regarding the prevalence, molecular detection, and antibiotic sensitivity test of Campylobacter spp. in broiler and layer poultry in organized farms and LBMs of Bangladesh [18-21]. However, campylobacteriosis in the major production system (small scale sector three category) in terms of occurrence and its comparison with good farm practices has yet to be explored.

Given the situation, it was pertinent to conduct this study that has confirmed (i) occurrence, (ii) molecular detection, and (iii) antimicrobial resistance pattern of Campylobacter spp. in broiler farms of rural Bangladesh. Further, the study has evaluated the Campylobacter positivity status among the two groups of farms such as good practice and conventional farms with an aim to decide the risk reduction options considering public health hazards. It is expected that this study will inform national polices on good poultry farming practices in the major production system considering emerging public threats and food safety grounds in low resource settings like Bangladesh.

\section{Materials and Methods}

\subsection{Ethics Statement}

The Ethical Committee of the Bangladesh Agricultural University, Mymensingh approved the study on 19 August 2020 under reference no. AWEEC/BAU/2020(26). The farms were selected after consultation with the sub-district (Upazila) livestock office of Department of Livestock Services, Bangladesh, and with the willingness of the farmers to participate in this study. Thus, a written consent was taken from each of the farm owner/managers during the collection of samples.

\subsection{Study Design and Location}

The cross-sectional survey was conducted in three poultry dominant districts (Dhaka, Gazipur and Tangail) of Bangladesh. The study utilized 32 broiler farms that comprised of 24 farms from Gazipur, 4 farms from Tangail and the remaining 4 farms from Dhaka districts were included under this survey after consultation with local livestock offices. The geospatial locations of the surveyed 
farms are presented in Figure 1. On the basis of density distribution of the broiler farms, more farms were enrolled from Gazipur district under this study.

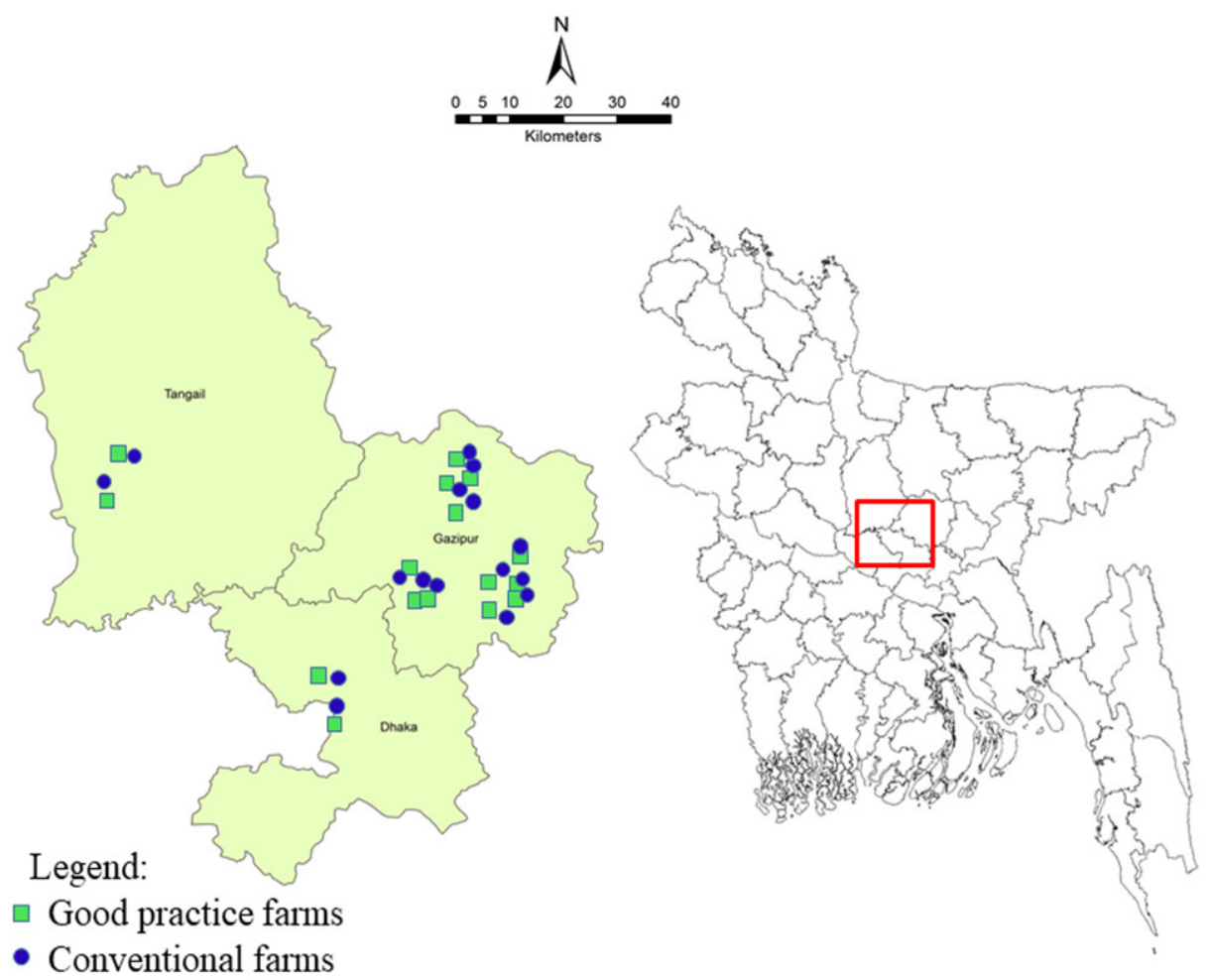

Figure 1. Location of broiler farms in three district of Bangladesh were included in this survey. Same number of farms were included in this study comprised of good practice broiler farms $(n=16)$ and conventional farms ( $n=16)$ ( 4 farms from Dhaka, 4 from Tangail and 24 from Gazipur districts).

\subsection{Selection of Farms}

Of 32 farms, an equal number of farms (good practice farms, $n=16$ and conventional farms, $n=16$ ) were included in this study with an inclusion criterion of a minimum flock size of $\geq 1000$ birds per farm under the sector three (small scale commercial) poultry production system.

\section{Development of Good Practice Farm}

The good practice broiler farms were developed through a collaborative program of Food and Agriculture Organization (FAO) of the United Nations and Department of Livestock Services (DLS), Bangladesh in poultry food safety where five key biological control measures (bacteria) for safe broiler production were addressed at the farm level. The key control measures (good agriculture practices) relating to germs were implemented at the farms' level, are presented in Table 1.

Additionally, the good practices farms were supported through providing intervention materials for improving farm biosecurity and a day-long participatory training focusing on key control measures on safe broiler production. The impact of the interventions was monitored periodically by a local committee of each sub-district for assessment of effectiveness of these activities. To evaluate the Campylobacter positivity status among the two groups of farms, an equal number of conventional farms $(n=16)$ were taken randomly to match with the good practice farms from the same locations (Figure 1 and Supplementary Table S1 appendix). 
Table 1. Five key biological control measures (bacteria) for safe broiler production.

\begin{tabular}{ll}
\hline \multicolumn{1}{c}{ Key Control Measures } & \multicolumn{1}{c}{ Areas of Intervention } \\
\hline $\begin{array}{l}\text { Protect poultry flock with } \\
\text { good biosecurity practices }\end{array}$ & $\begin{array}{l}\text { Perimeter fencing, netting at poultry sheds; poultry trucks \& cages are cleaned \& } \\
\text { disinfected before entry into farm; footwear are cleaned and disinfected before } \\
\text { entry and provision of quarantine facilities for suspected/possibly } \\
\text { infected poultry. }\end{array}$ \\
\hline $\begin{array}{l}\text { Use safe production } \\
\text { inputs that free of } \\
\text { biological hazards }\end{array}$ & $\begin{array}{l}\text { Commercial day-old-chicks or pullets reliable sources; veterinary health } \\
\text { certificate for free from infectious diseases e.g., Salmonella, Campylobacter etc, } \\
\text { and with certificate of origin, and water are free of biological hazards e.g., }\end{array}$ \\
\hline $\begin{array}{l}\text { Salmonella, Campylobacter. } \\
\text { Apply good animal } \\
\text { (part of good }\end{array}$ & $\begin{array}{l}\text { Vaccination against poultry diseases; age group separation e.g., buffer zones of } \\
\text { >30 m, and practice all-in-all-out, appropriate stocking density (1.6 to }\end{array}$ \\
agriculture practices) & $\begin{array}{l}\text { 2.0 sq.ft./bird depending on size of broiler); use probiotics for preventing the } \\
\text { pathogens; veterinary inspection before selling on good health status, and keep } \\
\text { proper records and documentation of farm. }\end{array}$ \\
\hline $\begin{array}{l}\text { Practice good } \\
\text { personal hygiene }\end{array}$ & $\begin{array}{l}\text { Ensure workers' health, wash hands after visiting toilet and handling live poultry } \\
\text { or poultry waste, and before entering poultry sheds; use PPE (boots \& gloves) } \\
\text { when working in poultry sheds or cleaning poultry sheds; workers who are sick, } \\
\text { with cuts or wounds or immunologically compromised should not work in } \\
\text { the farm. }\end{array}$ \\
\hline $\begin{array}{l}\text { Practice good poultry } \\
\text { waste management and } \\
\text { environmental control } \\
\text { (part of good } \\
\text { agriculture practices) }\end{array}$ & $\begin{array}{l}\text { Good poultry waste management (bury poultry waste with lime, compost), } \\
\text { good pest control, Keep farm environment clean with good drainage in the farm } \\
\text { and free from disused equipment and construction material in the farm. }\end{array}$ \\
\hline
\end{tabular}

\subsection{Sample Collection and Processing}

An equal number of samples were randomly collected via a convenient sampling technique before the selling of birds (35-45 day of a production cycle) from both categories of farms spanning from August to October 2017. A sample collection checklist was used for recording all samples collected from each farm (Supplementary Table S2). Of 352 different types sample, 36.36\% $(n=128)$ cloacal swab, $18.18 \%(n=64)$ feed, $18.18 \%(n=64)$ drinking water, $18.18 \%(n=64)$ attendants' hand rinse water, and $9.09 \%(n=32)$ whole carcasses were collected after slaughtering in poultry stalls of LBMs. Aseptic measures were maintained during collection of samples, the amount of which varied as per sample category as $100 \mathrm{~g}$ for meat (carcass) and feed, $500 \mathrm{~mL}$ for water and 1-5 $\mathrm{mL}$ or $\mathrm{mg}$ cloacal swabbed materials in sterile cotton swab, and $200 \mathrm{~mL}$ attendants' hand rinse water. The cotton swabs were preserved and transported in Cary Blair transport media. However, 32 whole carcass samples each represented a combination of breast, thigh, and drumstick. To overcome the sampling bias, three sub-samples of each sample category were randomly collected and pooled together from each farm. Immediate after collection, samples were kept in a plastic container and shifted to the laboratory of Department of Microbiology and Hygiene, Bangladesh Agricultural University (BAU), Mymensingh maintaining cool chain at $4-6{ }^{\circ} \mathrm{C}$ in an insulated foam box. The broiler farmers were informed duly on the research objectives so as to they could voluntarily involve with this study through arrangement of meetings in each sub-district livestock offices $(n=5)$ of three districts (Dhaka (1), Tangail (1) and Gazipur (3)).

\subsection{Isolation, Identification and Molecular Detection}

\subsubsection{Culture and Biochemical Tests}

The samples were processed immediately after arrival in the laboratory for bacteriological culture. Isolation of Campylobacter spp. was carried out as previously described [22]. In briefly, $100 \mu \mathrm{L}$ of homogenates of processed sample spread on the $0.45 \mu \mathrm{m}$ cellulose nitrate filter paper (Sartorius Stedim 
Biotech, Göttingen, Germany) that were placed on the surface of Blood base agar no. 2 (BBA) plate (HiMedia, Mumbai India) supplemented with 5\% sheep blood and allowed to stand for 30 min at room temperature. The filter was removed, and the medium plate was incubated at $37{ }^{\circ} \mathrm{C}$ for $48 \mathrm{~h}$ under microaerophilic conditions $\left(5 \% \mathrm{O}_{2}, 10 \% \mathrm{CO}_{2}\right.$, and $\left.85 \% \mathrm{~N}_{2}\right)$ using AnaeroPouch ${ }^{\circledR}$ MicroAero (Mitsubishi Gas Chemical Co., Inc., Tokyo, Japan). In BBA, grey, flat and irregularly spreading colonies were observed. The colonies from the selected media then sub-cultured onto the Blood agar base no. 2 with Skirrow supplement/growth supplement for getting a single and pure colony. To identify and differentiate between C. jejuni and C. coli, Gram staining and biochemical tests such as the catalase test, oxidase test, hippurate hydrolysis test, and motility test, were accomplished as earlier described [23,24]. Pure isolates were obtained in above techniques used for molecular assay.

\subsubsection{Molecular Detection}

In PCR assay, DNA was extracted from the pure culture of Campylobacter spp. via the boiling method [25]. For confirmation of the genus of Campylobacter, 16S rRNA gene-based PCR was done [26]. After confirmation of Campylobacter spp., hippuricase (hipO) gene-based PCR was accomplished for the identification of C. jejuni [27]. Those isolates presented as negative interpretation via hipO gene-based PCR were further detected as C. coli through $c d t A$ gene-based multiplex PCR assay as previously described [28]. The list of primers with thermal condition used in PCR are shown in Table 2. In briefly, for each isolate, $25 \mu \mathrm{L}$ of reaction mixture was prepared by adding $12 \mu \mathrm{L}$ master mixtures (Promega, Madison, WI, USA), $1 \mu \mathrm{L}$ forward primer (10 pmol), $1 \mu \mathrm{L}$ reverse primer (10 pmol) (BioServe Biotechnologies, Hyderabad, India), $3 \mu \mathrm{L}$ DNA template, and rest portion taken as deionized water in a PCR tube for amplification. The PCR reactions were carried out using a thermocycler (Astec, Fukuoka, Japan) as per manufacturer's instruction: initial denaturation with 1 cycle of 5 min at $94{ }^{\circ} \mathrm{C}$, 30 cycles each consisting of denaturation as shown in Table 2 and a final extension step of 10 min at $72{ }^{\circ} \mathrm{C}$. PCR products were visualized to gel electrophoresis (1.5-2\% agarose, Invitrogen, Carlsbad, CA, USA) and stained with ethidium bromide $\left(0.5 \mu \mathrm{g} \mathrm{mL}^{-1}\right)$ and de-stained with distilled water, each for $10 \mathrm{~min}$, before gel images were captured using a UV transilluminator (Biometra, Göttingen, Germany).

Table 2. Details of primers used in this study.

\begin{tabular}{|c|c|c|c|c|c|c|c|}
\hline Primers & Sequence $\left(5^{\prime}-3^{\prime}\right)$ & $\begin{array}{l}\text { Target } \\
\text { Gene }\end{array}$ & $\begin{array}{c}\text { Amplicon } \\
\text { Size (bp) }\end{array}$ & \multicolumn{3}{|c|}{ PCR Condition (30 Cycle) } & Reference \\
\hline $\begin{array}{c}\text { 16S9F } \\
16 \mathrm{~S} 1540 \mathrm{R}\end{array}$ & $\begin{array}{l}\text { GAGTTTGATCCTGGCTC } \\
\text { AAGGAGGTGATCCAGCC }\end{array}$ & 16S rRNA & 1530 & $94^{\circ} \mathrm{C}, 30 \mathrm{~s}$ & $47^{\circ} \mathrm{C}, 30 \mathrm{~s}$ & $72{ }^{\circ} \mathrm{C}, 90 \mathrm{~s}$ & [26] \\
\hline $\begin{array}{l}\text { HIP400F } \\
\text { HIP1134R }\end{array}$ & $\begin{array}{c}\text { GAAGAGGGTTTGGGTGGTG } \\
\text { AGCTAGCTTCGCATAATAACTTG }\end{array}$ & hipO gene & 735 & $94{ }^{\circ} \mathrm{C}, 30 \mathrm{~s}$ & $55^{\circ} \mathrm{C}, 30 \mathrm{~s}$ & $72{ }^{\circ} \mathrm{C}, 45 \mathrm{~s}$ & [27] \\
\hline $\begin{array}{l}\text { CcspAU1 } \\
\text { CcspAR1 }\end{array}$ & $\begin{array}{l}\text { ATTGCCAAGGCTAAAATCTC } \\
\text { GATAAAGTCTCCAAAACTGC }\end{array}$ & $C c c d t A$ & 329 & \multirow[t]{2}{*}{$94^{\circ} \mathrm{C}, 30 \mathrm{~s}$} & \multirow[t]{2}{*}{$53^{\circ} \mathrm{C}, 30 \mathrm{~s}$} & $72{ }^{\circ} \mathrm{C}, 30 \mathrm{~s}$ & \multirow{2}{*}{ [28] } \\
\hline $\begin{array}{l}\text { CfspAU1 } \\
\text { CfspAR1 }\end{array}$ & $\begin{array}{c}\text { AACGACAAATGTAAGCACTC } \\
\text { TATTTATGCAAGTCGTGCGA }\end{array}$ & $C f c d t A$ & 489 & & & & \\
\hline
\end{tabular}

\subsection{Antimicrobial Susceptibility Test}

All Campylobacter spp. strains were tested against eight antimicrobial agents in Bangladesh, viz. amoxycillin $(30 \mu \mathrm{g})$, azithromycin $(30 \mu \mathrm{g})$, ciprofloxacin $(5 \mu \mathrm{g})$, erythromycin $(30 \mu \mathrm{g})$, gentamicin $(10 \mu \mathrm{g})$, tetracycline $(30 \mu \mathrm{g})$, streptomycin $(10 \mu \mathrm{g})$ and norfloxacin (10 $\mu \mathrm{g})$ (HiMedia, Mumbai, India) by disk diffusion method [29]. The zones of growth inhibition were related with the zone diameter interpretative standards as labeled by the Clinical and Laboratory Standard Institute [30], and thus inferred i.e., susceptible (S), intermediate resistant (I) or resistant (R) to the antimicrobial agents. E. coli strain ATCC 25922 was used as a quality control organism. All interpretations were verified by performing a minimum of two replicates of the disk diffusion assay. 


\subsection{Data Management and Statistical Evaluation}

The data for laboratory test were taken and recorded in Microsoft Excel ${ }^{\circledR}$ worksheet and imported into Epi Info 7 program [31] for statistical analysis. The categorical data were presented as proportion (\%). Chi-square tests were performed to assess the correlation of positivity status among the various locations (sub-district and district) and sample categories (cloacal swab, feed, water, attendants' hand rinse water, and whole carcass) with good practice broiler farms versus conventional farms. Thereby, $p \leq 0.05$ was used to determine statistical significance.

\section{Results}

\subsection{Occurrence of Campylobacter spp.}

The survey confirmed an overall occurrence of Campylobacter spp. as 26.4\% (93/352) through culture-based methods and biochemical tests. Further, a single representative colony of Campylobacter was isolated as a pure culture from each of 93 positive samples. A genus specific $16 \mathrm{~S}$ rRNA PCR assay was used for generating an expected $1530 \mathrm{bp}$ amplicon size, and validating the identity as Campylobacter spp. Among the three districts, Tangail was recorded as highest prevalence (29.5\%) of Campylobacter spp. followed by Gazipur (26.5\%) and Dhaka districts (22.7\%). Relating to the district level positivity status, there was no significant difference observed (Table 3) and sub-district-wise contamination of Campylobacter spp., Kapasia was found to be highest degree of contamination (39.8\%) followed by Sadar Tangail (29.6\%) and Savar (22.7\%) sub-districts. However, Sreepur and Sadar, Gazipur sub-districts were captured at lower levels of Campylobacter spp. infection (19.3\% and 20.4\% respectively). The studied sub-districts were found to be significant with Campylobacter infection $(p=0.014)$ in this study (Table 3).

Table 3. Occurrence of Campylobacter spp. in broiler farms of 3 districts of Bangladesh ( $N=352$ samples).

\begin{tabular}{cccccc}
\hline $\begin{array}{c}\text { District/Sub-District } \\
\text { (Upazila) }\end{array}$ & $\begin{array}{c}\text { No. of } \\
\text { Sample }\end{array}$ & $\begin{array}{c}\text { No. of } \\
\text { Positive } \\
\text { Samples }\end{array}$ & $\begin{array}{c}\text { Occurrence } \\
\mathbf{( \% )}\end{array}$ & 95\% CI & $\begin{array}{c}p \text { Value } \\
\text { (Pearson's Chi- } \\
\text { Squared Test) }\end{array}$ \\
\hline District & 264 & 70 & 26.5 & $21.3-32.3$ & \\
Gazipur & 44 & 13 & 29.5 & $16.8-45.2$ & 0.76 \\
Tangail & 44 & 10 & 22.7 & $11.5-37.8$ & \\
Dhaka & & & & & \\
\hline Sub-District (Upazila) & 88 & 18 & 20.4 & $12.6-30.4$ & \\
Sadar, Gazipur & 88 & 17 & 19.3 & $11.7-29.1$ & \\
Sreepur, Gazipur & 88 & 35 & 39.8 & $29.4-50.8$ & 0.014 \\
Kapasia, Gazipur & 44 & 13 & 29.6 & $16.8-45.2$ & \\
Sadar, Tangail & 44 & 10 & 22.7 & $11.4-37.8$ & \\
Savar, Dhaka & 352 & 93 & 26.4 & $21.9-31.3$ & \\
\hline Overall & 34 & & & \\
\hline
\end{tabular}

a Samples included cloacal swab, feed, drinking water, attendants' hand rinse water, and whole carcasses.

Among the two groups of farms, the overall occurrence of Campylobacter spp. was estimated as $36.4 \%$ and $16.5 \%$ in conventional farms and good practice farms respectively. Of collected different samples, the contamination of Campylobacter spp. in whole carcass was recorded as 56.3\% (nine in 16) and $18.8 \%$ (three in 16) in conventional farms and good practice farms respectively. Similarly, $48.4 \%$ (31 in 64), 20.3\% (13 in 64) in cloacal swab, $25 \%$ (eight in 32), and 15.63\% (five in 32 ) in feed, $25 \%$ (eight in 32 ) and $12.5 \%$ (four in 32 ) in attendants' hand rinse water, and $25 \%$ (eight in 32 ) and $12.5 \%$ (four in 32) in drinking water were captured in conventional and good practice broiler farms respectively. Considering the level of contamination, the conventional farms were found to demonstrate higher occurrence of Campylobacter spp. than the good practice farms, including all categories of sample and found to be statistically significant (Table 4). 
Table 4. Occurrence of Campylobacter spp. in different types samples among two groups of broiler farms (good practice farms versus conventional farms).

\begin{tabular}{|c|c|c|c|c|c|}
\hline $\begin{array}{c}\text { Sample } \\
\text { Type/Parameters }\end{array}$ & Farm Type $(n)$ & $\begin{array}{c}\text { No. of } \\
\text { Positive } \\
\text { Samples }\end{array}$ & $\begin{array}{c}\text { Occurrence } \\
(\%)\end{array}$ & $\begin{array}{c}95 \% \\
\text { Confidence } \\
\text { Interval }\end{array}$ & $\begin{array}{c}p \text { Value } \\
\text { (Pearson's Chi- } \\
\text { Squared Test) }\end{array}$ \\
\hline \multirow{3}{*}{ Cloacal swab } & Conventional farms $(n=64)$ & 31 & 48.4 & $35.7-61.3$ & \multirow{3}{*}{0.001} \\
\hline & Good practice farms $(n=64)$ & 13 & 20.3 & $11.3-32.2$ & \\
\hline & Both farms $(n=128)$ & 44 & 34.4 & $26.2-43.3$ & \\
\hline \multirow{3}{*}{ Feed } & Conventional farms $(n=32)$ & 8 & 25 & $11.5-43.4$ & \multirow{3}{*}{0.35} \\
\hline & Good practice farms $(n=32)$ & 5 & 15.6 & $5.3-32.8$ & \\
\hline & Both farms $(n=64)$ & 13 & 20.3 & $11.3-32.2$ & \\
\hline \multirow{3}{*}{$\begin{array}{l}\text { Drinking water } \\
\text { for poultry }\end{array}$} & Conventional farms $(n=32)$ & 8 & 25 & $11.5-43.4$ & \multirow{3}{*}{0.20} \\
\hline & Good practice farms $(n=32)$ & 4 & 12.5 & $3.5-29$ & \\
\hline & Both farms $(n=64)$ & 12 & 18.8 & $10.1-30.5$ & \\
\hline \multirow{3}{*}{$\begin{array}{l}\text { Attendants' } \\
\text { hand rinsed }\end{array}$} & Conventional farms $(n=32)$ & 8 & 25 & $11.5-43.4$ & \multirow{3}{*}{0.20} \\
\hline & Good practice farms $(n=32)$ & 4 & 12.5 & $3.5-29$ & \\
\hline & Both farms $(n=64)$ & 12 & 18.8 & $10.1-30.5$ & \\
\hline \multirow{3}{*}{ Whole carcass } & Conventional farms $(n=16)$ & 9 & 56.3 & $29.9-80.2$ & \multirow{3}{*}{0.02} \\
\hline & Good practice farms $(n=16)$ & 3 & 18.8 & $4-45.6$ & \\
\hline & Both farms $(n=32)$ & 12 & 37.50 & $21.1-56.3$ & \\
\hline \multirow{3}{*}{ All samples } & Conventional farms $(n=176)$ & 64 & 36.4 & $29.3-43.9$ & \multirow{3}{*}{0.000} \\
\hline & Good practice farms $(n=176)$ & 29 & 16.5 & $11.3-22.8$ & \\
\hline & Both farms $(N=352)$ & 93 & 26.4 & $21.9-31.3$ & \\
\hline
\end{tabular}

\subsection{Molecular Detection by Polymerase Chain Reaction (PCR)}

All Campylobacter isolates presented specific amplification (1530 bp) through genus specific (16S rRNA gene) polymerase chain reaction (PCR). However, hipO gene-based PCR was completed to identify C. jejuni and all C. jejuni isolates presented specific amplification (735 bp). In addition, $c d t A$ gene-based multiplex PCR was conducted for the confirmation of $C$. coli and obtained specific amplification (329 bp) (Supplementary Figure S1).

Of the 93 isolates, $67.7 \%(n=63)$ as $C$. jejuni and remaining $32.3 \%(n=30)$ as $C$. coli were confirmed through the molecular detection. In good practice farms, $16.5 \%$ (29 in 176) of samples were found to be positive with Campylobacter that showed C. jejuni and C. coli occurrence as $11.4 \%$ (20 in 176) and 5.1\% (nine in 176) respectively (Figure 2). In addition, in 36.4\% (64 in 176) samples from conventional farms were confirmed with Campylobacter infection, where C. jejuni and C. coli positive status was $24.4 \%$ (43 in 176) and $11.9 \%$ (21 in 176) respectively (Figure 2). However, the overall occurrence of $C$. jejuni and C. coli was confirmed as 17.9\% (63 in 352) and 8.5\% (30 in 352), respectively (Figure 2).

\subsection{Antimicrobial Susceptibility Test}

Of 63 isolates of C. jejuni, 73\% $(n=56), 87.3 \%(n=55), 54 \%(n=34)$, and $63.5 \%(n=40)$ were found to be susceptible to ciprofloxacin, gentamicin, norfloxacin, and streptomycin, respectively. In contrast, out of 30 isolates of C. coli, $60 \%(n=18), 73.3 \%(n=22), 63.4 \%(n=19)$, and $70 \%(n=21)$ were captured as to be susceptible to ciprofloxacin, gentamicin, norfloxacin, and streptomycin, respectively (Figure 3).

\subsection{Antimicrobial Resistance Pattern}

Out of 63 isolates of C. jejuni, 34.9\% $(n=22)$ were revealed resistant against three or more antimicrobial agents as multidrug resistant namely amoxicillin, streptomycin, tetracycline, erythromycin, ciprofloxacin, amoxicillin, norfloxacin, and azithromycin. Of 22 isolates, $19 \%(n=12)$ were presented as resistant against three antimicrobials as AMX-S-TE $(7.9 \%, n=5)$ and E-S-CIP $(11.1 \%$, $n=7)$, respectively, and $15.9 \%(n=10)$ were shown to be multidrug resistant against four antimicrobial agents (AMX-NOR-AZM-TE). Conversely, $14.3 \%(n=9)$ isolates of $C$. jejuni, were shown to be resistant against two antimicrobials, namely AMX-TE $(6.4 \%, n=4)$ and AMX-S $(7.9 \%, n=5)$, respectively, and $50.8 \%(n=32)$ of isolates were shown to be resistant against a single antimicrobial agent (Table 5$)$. 


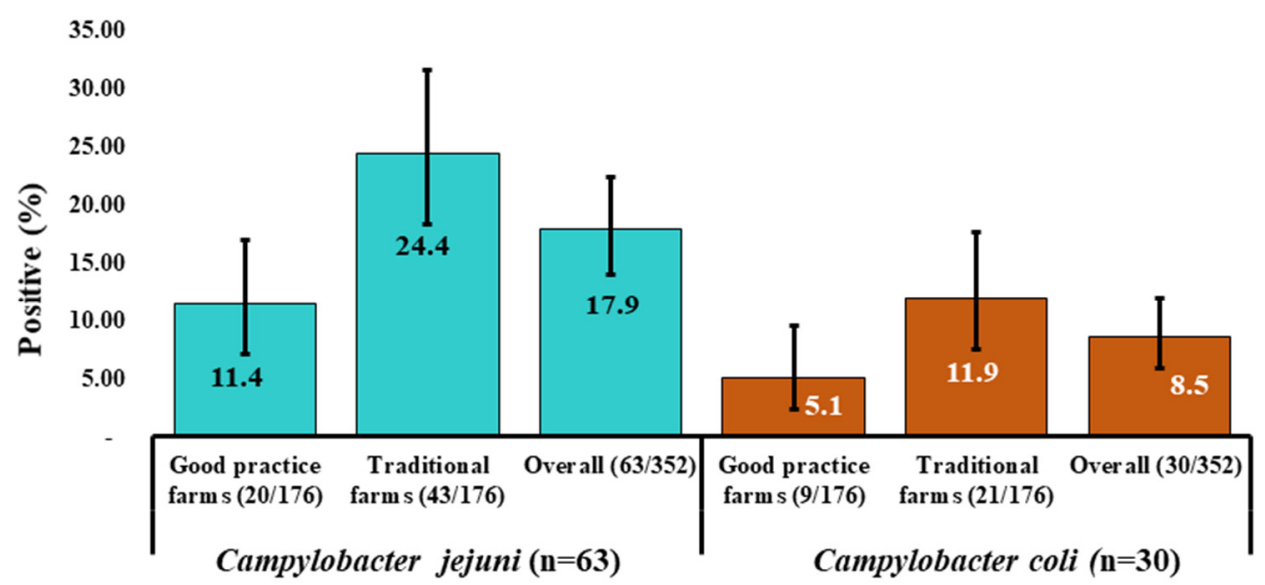

Figure 2. Distribution of occurrence of Campylobacter isolates ( $95 \%$ Confidence interval) that included C. jejuni $(n=63)$ and C. coli $(n=30)$ in two groups farms (good practice and traditional farms) in three districts of Bangladesh. The overall occurrence of Campylobacter spp. among the groups were significantly different $(p=0.000)$.

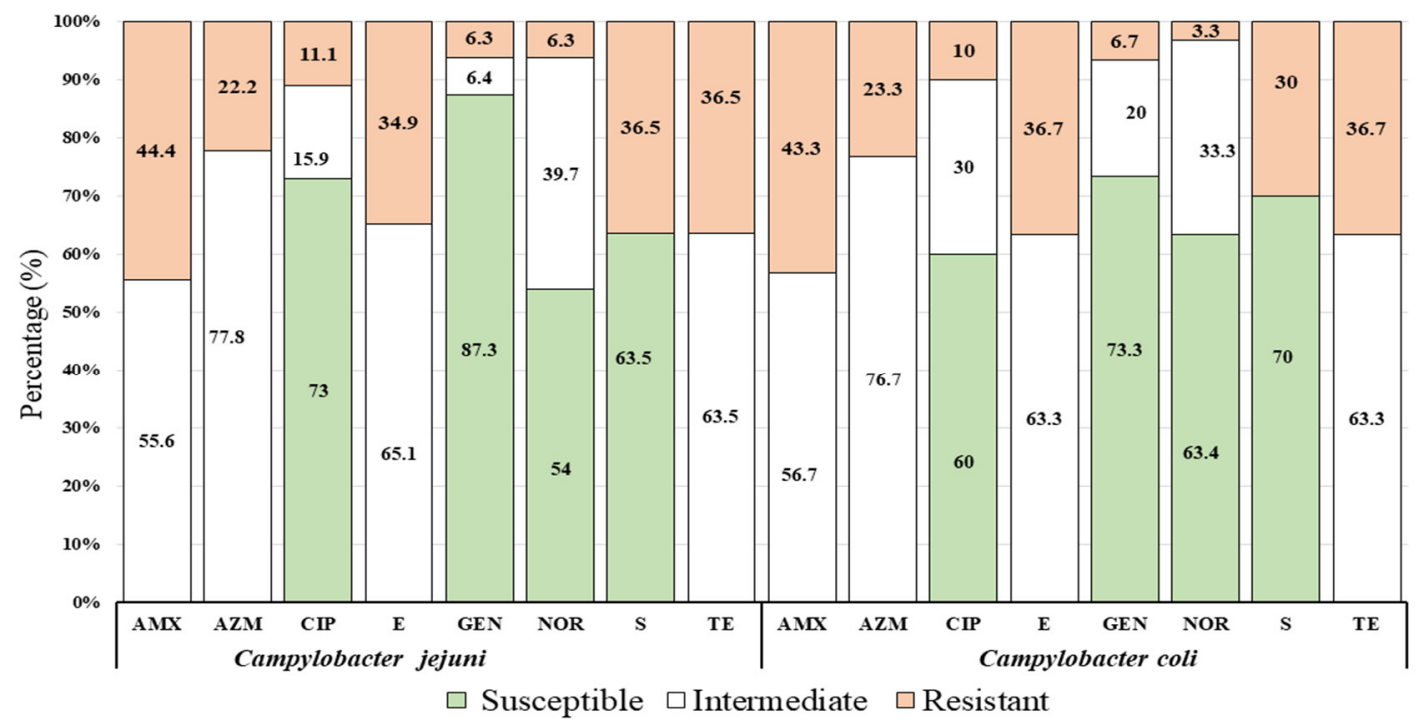

Figure 3. Proportion of antimicrobial susceptibility profile of Campylobacter spp. (C. jejuni and C. coli) against common eight (8) antimicrobial agents with standard doses ( $\mu \mathrm{g})$ : Amoxicillin (AMX, $30 \mu \mathrm{g})$, Azithromycin (AZM, $30 \mu \mathrm{g})$, Ciprofloxacin (CIP, $5 \mu \mathrm{g})$, Erythromycin (E, $30 \mu \mathrm{g})$, Gentamycin (GEN, $10 \mu \mathrm{g}$ ), Norfloxacin (NOR, $10 \mu \mathrm{g}$ ), Streptomycin $(\mathrm{S}, 10 \mu \mathrm{g}$ ), and Tetracycline (TE, $30 \mu \mathrm{g}$ ) showed in three groups (susceptible, intermediate, and resistant) of the resistant pattern in accordance to Clinical and Laboratory Standards Institute [30].

Out of 30 isolates, C. coli, 30\% $(n=9)$ were captured as multidrug resistant. Of 9 isolates, $16.7 \%$ $(n=5)$ isolates were presented resistant against three antimicrobials viz. AMX-S-TE $(6.7 \%, n=2)$ and E-S-CIP $(10 \%, n=3)$ respectively, and 13.3\% $(n=4)$ were shown as multidrug resistant against four antimicrobials (AMX-NOR-AZM-TE). In this study $13.3 \%(n=4)$ isolates were shown to be resistant against two antimicrobials, namely $\operatorname{AMX-TE}(6.7 \%, n=2)$ and AMX-S $(6.7 \%, n=2)$, respectively, and $56.7 \%(n=17)$ isolates were presented as resistant simply to a single antimicrobial agent (Table 5). 
Table 5. Distribution of antimicrobial resistance pattern among the isolated C. jejuni $(n=63)$ and C. coli $(n=30)$ strains from broiler farms.

\begin{tabular}{|c|c|c|c|c|c|}
\hline \multirow{2}{*}{$\begin{array}{l}\text { Resistance } \\
\text { against } \\
\text { Antimicrobials }\end{array}$} & \multirow{2}{*}{$\begin{array}{l}\text { Resistance } \\
\text { Patterns }\end{array}$} & \multicolumn{2}{|c|}{ C. jejuni $(n=63)$} & \multicolumn{2}{|c|}{ C. $\operatorname{coli}(n=30)$} \\
\hline & & $\begin{array}{l}\text { No. (\%) of } \\
\text { Strains }\end{array}$ & $\begin{array}{c}\text { Subtotal } \\
{[\text { No. }(\%)]}\end{array}$ & $\begin{array}{l}\text { No. (\%) } \\
\text { of Strains }\end{array}$ & $\begin{array}{l}\text { Subtotal } \\
{[\text { No. }(\%)]}\end{array}$ \\
\hline \multicolumn{6}{|c|}{ Against One to Two Antimicrobial Agents } \\
\hline \multirow[t]{7}{*}{ Against one } & AMX & $5(6.4)$ & $32(50.8)$ & $3(10)$ & \\
\hline & E & $5(7.9)$ & & $4(13.3)$ & \\
\hline & AZM & $5(7.9)$ & & $3(10)$ & \\
\hline & S & $5(7.9)$ & & $1(3.3)$ & $17(56.7)$ \\
\hline & E & $4(6.4)$ & & $3(10)$ & \\
\hline & GEN & $4(6.4)$ & & $2(6.7)$ & \\
\hline & NOR & $5(7.9)$ & & $1(3.3)$ & \\
\hline \multirow[t]{2}{*}{ Against two } & AMX-TE & $4(6.4)$ & $9(14.3)$ & $2(6.7)$ & $4(13.4)$ \\
\hline & AMX-S & $5(7.9)$ & & $2(6.7)$ & \\
\hline \multicolumn{6}{|c|}{ Against Three or More Antimicrobial Agents } \\
\hline \multirow[t]{2}{*}{ Against three } & AMX-S-TE & $5(7.9)$ & $12(19)$ & $2(6.7)$ & $5(16.7)$ \\
\hline & E-S-CIP & 7 (11.1) & & $3(10)$ & \\
\hline Against four & AMX-NOR-AZM-TE & $10(15.9)$ & $10(15.9)$ & $4(13.3)$ & $4(13.3)$ \\
\hline \multicolumn{2}{|c|}{$\begin{array}{l}\text { Total against three or more } \\
\text { antimicrobials }\end{array}$} & $22(34.9)$ & & $9(30)$ & \\
\hline
\end{tabular}

\section{Discussion}

The study was conducted in three major poultry districts of Bangladesh neighboring the capital city and these districts provide chicken meat and eggs for the consumption of city dwellers. Bangladesh is now self-reliant in meat production, of which the maximum contribution comes from broiler meat as the government has taken various measures to support the country's livestock sector [32]. A lack of substantial data prompts the difficulty of understanding the current status of poultry diseases [33]. Among the different types of poultry diseases, both bacterial and viral origin are the major burden in poultry sectors, of which campylobacteriosis and salmonellosis are most prevalent [34]. Therefore, this survey was sensible to estimate the distribution of Campylobacter spp., in major broiler production farms that will support to the national disease control program as a baseline data.

We estimated an overall positive status of Campylobacter spp. as $26.4 \%$ (95\% CI: $21.9-31.3 \%$ ) in boiler farms. The overall positivity status estimated under this study has been supported by other research both in home and abroad. A positive status of 32\% Campylobacter in broiler flocks was found in India [35], and 29\% and 21.5\% in Pakistan [36,37]. However, Campylobacter occurrence in broiler samples was confirmed as $32 \%$ and $40.5 \%$ in Bangladesh [20,21]. Conversely, relatively a higher prevalence of Campylobacter in broiler samples was reported in Sri Lanka as 67\% as a result of higher temperature in this country comparing to the other parts of Indian subcontinent [38]. In Europe, the mean prevalence of Campylobacter in colonized broiler and carcasses was reported as significantly higher than others as $71.2 \%$ and $75.8 \%$ respectively [9]. Moreover, Campylobacter colonization was stated as approximately $90 \%$ in broiler flocks in the USA [39] and 65\% in Poland [40].

In this survey, the degree of higher contamination was documented in whole carcass (56.3\%). This finding has been confirmed closely by many studies in Asian counties, Campylobacter positivity was documented as 59\% Pakistan and 40\% in Sri Lanka in broiler meat samples respectively [37,38]. Moreover, Campylobacter positivity was established in broiler carcasses samples as $45.1 \%$ in China [41], $31 \%$ in Thailand [42], 30\% in Vietnam [43], and $80.9 \%$ in Cambodia [44]. However, noticeably, a higher prevalence (75.8\%) of Campylobacter spp. was documented in broiler carcass of European countries [9].

The drinking water of $18.8 \%(12 / 64)$ poultry farms was found to be contaminated with Campylobacter. The result obtained from this study was corroborated by another research conducted in Bangladesh 
as presence of 33\% Campylobacter contamination in drinking water samples from broiler farms [21]. The present study further confirmed as 18.8\% (12/64) farm attendants' hand rinsed water were found to be Campylobacter positive as they were exposed to contaminated flocks and water or even poultry cages during working at the farms. The Campylobacter can survive in hands at a log CFU loss in 45 min [45] and human moist clothing $0.5-24 \mathrm{~h}$ at room temperature [46]. The likelihood of enteric infections among poultry attendants is enormous as they become exposed to Campylobacter contamination. Therefore, personal hygienic measures to be taken immediately after working at poultry farms. However, use of protective materials like mask and gloves, aprons are needed that will minimize further exposure of zoonotic pathogens [47,48]. Likewise, the study confirmed 20.3\% (13 in 64) feed samples found to be positive with Campylobacter that disagrees with the other research as $0 \%$ Campylobacter positive status confirmed [21]. Since the feed sampling was accomplished using the pool samples (both from feeder and stored feed) from the surveyed farms, this positivity status of the feed sample due to cross contamination from the infected feeds at poultry feeder.

The study has enumerated as higher occurrence of Campylobacter spp. in conventional farms (36.4\%, 95\% CI: 29.3-43.9\%) in comparison to the good practice farms (16.5\%, 95\% CI: 11.3-22.8\%). This finding is empirically supported by other research [49] as high standards of biosecurity measures will reduce the Campylobacter contamination by $20-40 \%$ lower than those farms with lower standards. Moreover, biosecurity measurement is important targeted to Campylobacter control when colonization happens in a poultry flocks the horizontal spread can be prompt [50].The likelihood of bacterial infection was lower in best practice farms and found to be more protective than the poor practice farms because of the implementation of key control measures related to farm biosecurity and GAP practices, i.e., provision of perimeter fencing, netting of the farm to control entrance of wild and domestic animals and birds, controlling human movement inside the farm, dedicated footwear, and footwear cleaning at the entry to the poultry shed with disinfectants, all in all out practices, along with use of safe production inputs (DOC, feed, and water) [15,51-53]. In this study, the overall occurrence of C. jejuni (17.9\%, 63 in 352) was found to be higher than C. coli (8.5\%, 30 in 352). Among the isolates, $67.74 \%$ C. jejuni and $32.26 \%$ C. coli were confirmed through gene specific PCR assays. This observation was consistent with the many studies $[21,36,37,54,55]$. However, a higher occurrence of $51 \%$ C. jejuni and $35.5 \%$ C. coli were detected in broiler meat in Europe [9]. In contrast, some researchers reported C. coli is the more abundance species in broiler poultry $[38,56]$.

This study recognized the antimicrobial resistance patterns of C. jejuni and C. coli as $44.4 \%$ and $43.3 \%$ to amoxicillin, $36.5 \%$ and $36.7 \%$ to tetracycline, and $34.9 \%$ and $36.7 \%$ to erythromycin, respectively. Similar observations have been proven by many researchers in Bangladesh $[13,18,19]$. However, a dissonant finding was confirmed as C. jejuni and C. coli are resistant to 5\%, $11.1 \%$ to erythromycin and $85 \%, 24.4 \%$ to tetracycline, respectively [38].

In this study, $34.9 \%(n=22)$ C. jejuni and 30\% $(n=9)$ C. coli isolates were captured as multidrug resistant against three or more antimicrobial agents, viz, amoxicillin, streptomycin, tetracycline, erythromycin, ciprofloxacin, amoxicillin, norfloxacin and azithromycin. However, these are the most commonly used in poultry rearing in Bangladesh. As selective pressure is usually accountable for AMR development through indiscriminately use antibiotics as feed additives and growth promoters in poultry feed [13] that might have a direct association with the development of multidrug resistance Campylobacter in poultry [21]. However, government efforts have focused on the prudent use of antibiotics only for therapeutic purposes [57]. These resistant profiles of Campylobacter spp. as multidrug resistant are comparable to the observations of some other researchers in Bangladesh [13,19]. However, another study in Bangladesh detected as $86.36 \%$ C. jejuni and 100\% C. coli isolates were found to be as multidrug resistant [18]. Furthermore, $49 \%$ and $42 \%$ isolates of C. jejuni and C. coli, respectively were confirmed as multidrug resistant and resistant to three or more antimicrobial agents in samples collected from poultry farms and LBMs of Bangladesh [21]. The spread of multidrug resistant bacteria can cause infections that are resistant to antibiotic treatment [58] and the transmission of residual antimicrobials through the food chain can trigger serious health problems, like gastrointestinal and neurological 
ailments, tissue damage, and hypersensitivity in animals and humans [59]. Therefore, the use of antimicrobials in food animal production should be minimized considering possible alternative options, like prebiotics, probiotics, and herbal extracts, for both prophylactic and therapeutic use in poultry production $[60,61]$.

The study has some limitations as only single colony was used from each sample for subculture and finally molecular detection for species confirmation. This indicates that samples with more than one species of Campylobacter could not be captured under this study. Moreover, the samples were collected considerably from a limited number farms and did not to cover all poultry dominant districts of Bangladesh. In this regard, an in-depth longitudinal survey, including potential risk factors, is needed covering all poultry dominant districts with an aim to identify the potential drivers of Campylobacter spp. introduction and subsistence along the value chain (farm to table) as remedial options to be appropriate in the context of Bangladesh.

\section{Conclusions}

The study confirmed a substantial degree of Campylobacter contamination in a wide range of samples of a major poultry production system that signifies a huge public health concern. In addition, some isolates were defined as multidrug resistant, which creates extra burden for public health. In this regard, raising farmers' awareness regarding good farm practices, including biosecurity measures, and the prudent use of antibiotics along with personal hygiene for poultry keepers need to be ensured through participatory training under a one health approach. These measures will pave the way for minimizing the burden of multidrug resistant poultry origin Campylobacter pathogens.

Supplementary Materials: Supplementary Materials could be found at http://www.mdpi.com/2076-2607/8/11/ 1778/s1. The data that support the findings of this study are available at online. Table S1. List of the farms (good practice and conventional farms) from 5 sub-districts of 3 districts of Bangladesh. Sample is presented under each category as pooled sample of three subsamples from each farms. Equal number of samples $(n=176)$ were collected from each category of farms, Table S2. Sample collection checklist and Figure S1. 16S rRNA gene-based PCR to identify Campylobacter genus (a), hipO gene-based PCR to identify C. jejuni (b), and $c d t A$ gene-based multiplex PCR assay to identify C. coli (c). In all figures, lanes: 1 and 8, 100 bp DNA ladder (Promega, Madison, WI, USA); lanes 2-5, representative positive isolates; lane 6, positive control (C. jejuni ATCC 33560 in picture a and b, and C. coli ATCC 33559 in picture c); and lane 7, negative control (Escherichia coli ATCC 25922).

Author Contributions: Conceptualization, B.A., M.N.U. and S.M.L.K.; methodology, S.M.L.K., B.A., M.N.U., D.M. and A.H.M.T.A.; data analysis, M.N.U. and S.S.I.; writing-original draft preparation, B.A. and M.N.U.; writing-review and editing, S.M.L.K., S.S.I. and A.K.M.Z.H. All authors have read and agreed to the published version of the manuscript.

Funding: This study was supported by FAO-UN under the project named "Improving Food Safety Program in Bangladesh (GCP/BGD/047/NET)" in collaboration with the Department of Livestock of Services under the Ministry of Fisheries and Livestock (MoFL), Bangladesh.

Acknowledgments: We appreciate the kind facilitation and valuable suggestions from Technical Expert, Food Safety Program of FAO of United Nations (FAO-UN), Bangladesh, for conducting the study. We are indebted to sub-district (Upazila) and district livestock officers for their cooperation for farm selection under this study, and we are also grateful to poultry farmers/attendants for their assistant to sample collection.

Conflicts of Interest: The authors declare no conflict of interest.

\section{References}

1. Kabir, S.M.L.; Kikuchi, K.; Asakura, M.; Shiramaru, S.; Tsuruoka, N.; Goto, A.; Hinenoya, A.; Yamasaki, S. Evaluation of a cytolethal distending toxin $(c d t)$ gene-based species-specific multiplex PCR assay for the identification of Campylobacter strains isolated from diarrheal patients in Japan. Jpn. J. Infect. Dis. 2011, 64, 19-27. [PubMed]

2. Shane, S. Campylobacter infection of commercial poultry. Rev. Sci. Tech. Off. Int. Epiz. 2000, 19, 376-385. [CrossRef] [PubMed]

3. Sahin, O.; Morishita, T.Y.; Zhang, Q. Campylobacter colonization in poultry: Sources of infection and modes of transmission. Anim. Health Res. Rev. 2002, 3, 95-105. [CrossRef] [PubMed]

4. Kaakoush, N.O.; Castaño-Rodríguez, N.; Mitchell, H.M.; Man, S.M. Global epidemiology of Campylobacter infection. Clin. Microbiol. Rev. 2015, 28, 687-720. [CrossRef] 
5. European Food Safety Authority and European Centre for Disease Prevention and Control. EU Summary Report on trends and sources of zoonoses, zoonotic agents and food-borne outbreaks in 2016. EFSA J. 2017, 12, e05077. [CrossRef]

6. Hansson, I.; Sandberg, M.; Habib, I.; Lowman, R.; Engvall, E. Knowledge gaps in control of Campylobacter for prevention of campylobacteriosis. Transbound. Emerg. Dis. 2018, 65 (Suppl. 1), 30-48. [CrossRef]

7. Nyati, K.K.; Nyati, R. Role of Campylobacter jejuni infection in the pathogenesis of Guillain-Barré syndrome: An update. BioMed Res. Int. 2013, 2013, 852195. [CrossRef]

8. Skarp, C.; Hänninen, M.-L.; Rautelin, H. Campylobacteriosis: The role of poultry meat. Clin. Microbiol. Infect. 2016, 22, 103-109. [CrossRef]

9. European Food Safety Authority (EFSA). Analysis of the baseline survey on the prevalence of Campylobacter in broiler batches and of Campylobacter and Salmonella on broiler carcasses, in the EU, 2008-Part B: Analysis of factors associated with Campylobacter colonisation of broiler batches and with Campylobacter contamination of broiler carcasses; and investigation of the culture method diagnostic characteristics used to analyse broiler carcass samples. EFSA J. 2010, 8. [CrossRef]

10. Ridley, A.; Morris, V.; Gittins, J.; Cawthraw, S.; Harris, J.; Edge, S.; Allen, V. Potential sources of Campylobacter infection on chicken farms: Contamination and control of broiler-harvesting equipment, vehicles and personnel. J. Appl. Microbiol. 2011, 111, 233-244. [CrossRef]

11. Agyare, C.; Boamah, V.E.; Zumbi, C.N.; Osei, F.B. Antibiotic Use in Poultry Production and Its Effects on Bacterial Resistance. In Antimicrobial Resistance-A Global Threat; IntechOpen: Rijeka, Croatia, 2018. Available online: https:/www.intechopen.com/books/antimicrobial-resistance-a-global-threat/antibioticuse-in-poultry-production-and-its-effects-on-bacterial-resistance (accessed on 11 November 2020).

12. Iovine, N.M.; Blaser, M.J. Antibiotics in animal feed and spread of resistant Campylobacter from poultry to humans. Emerg. Infect. Dis. 2004, 10, 1158-1159. [CrossRef] [PubMed]

13. Kabir, S.M.L.; Sumon, M.; Amin, M.M.; Yamasaki, S. Isolation, identification and antimicrobial resistance patterns of Campylobacter species from broiler meat sold at KR Market of Bangladesh Agricultural University Campus, Mymensingh. J. Agric. Food Technol. 2014, 4, 15-21.

14. Englen, M.D.; Ladely, S.R.; Fedorka-Cray, P.J. Isolation of Campylobacter and Identification by PCR. In PCR Detection of Microbial Pathogens; Springer: Berlin/Heidelberg, Germany, 2003; pp. 109-121.

15. Fraser, R.W.; Williams, N.T.; Powell, L.F.; Cook, A.J.C. Reducing Campylobacter and salmonella infection: Two studies of the economic cost and attitude to adoption of on-farm biosecurity measures. Zoonoses Public Health 2010, 57, e109-e115. [CrossRef] [PubMed]

16. Yap, T. Guidelines on Improving Food Safety in Poultry Value Chain in Bangladesh; Department of Livestock Services (DLS) \& Food and Agriculture Organization, Food Safety Program (FAO-FSP): Dhaka, Bangladesh, 2015.

17. Dolberg, F. Poultry Sector Country Review, Bangladesh. 2008. Available online: http://www.fao.org/3/aak069e.pdf (accessed on 29 September 2020).

18. Kabir, S.M.L.; Islam, J.; Suman, M.H.; Khan, M.S.R.; Yamasaki, S. Isolation, identification and antimicrobial susceptibility profiles of Campylobacter species with assessment of their risk factors in broiler flocks of Bangladesh Agricultural University Poultry Farm. J. Basic Appl. Sci. Res. 2014, 4, 160-168.

19. Islam, M.K.; Kabir, S.M.L.; Haque, A.K.M.Z.; Sarker, Y.A.; Sikder, M.H. Molecular detection and characterization of Escherichia coli, Salmonella spp. and Campylobacter spp. isolated from broiler meat in Jamalpur, Tangail, Netrokona and Kishoreganj districts of Bangladesh. Afr. J. Microbiol. Res. 2018, 12, 761-770. [CrossRef]

20. Hasan, M.M.; Talukder, S.; Mandal, A.K.; Tasmim, S.T.; Parvin, M.S.; Ali, M.Y.; Sikder, M.H.; Islam, M.T. Prevalence and risk factors of Campylobacter infection in broiler and cockerel flocks in Mymensingh and Gazipur districts of Bangladesh. Prev. Vet. Med. 2020, 180, 105034. [CrossRef]

21. Neogi, S.B.; Islam, M.M.; Islam, S.K.S.; Akhter, A.H.M.T.; Sikder, M.M.H.; Yamasaki, S.; Kabir, S.M.L. Risk of multi-drug resistant Campylobacter spp. and residual antimicrobials at poultry farms and live bird markets in Bangladesh. BMC Infect. Dis. 2020, 20, 278. [CrossRef]

22. Shiramaru, S.; Asakura, M.; Inoue, H.; Nagita, A.; Matsuhisa, A.; Yamasaki, S. A cytolethal distending toxin gene-based multiplex PCR assay for detection of Campylobacter spp. in stool specimens and comparison with culture method. J. Vet. Med. Sci. 2012, 74, 857-862. [CrossRef]

23. Jamshidi, A.; Bassami, M.; Farkhondeh, T. Isolation and identification of Campylobacter spp. and Campylobacter coli from poultry carcasses by conventional culture method and multiplex PCR in Mashhad, Iran. Iran. J. Vet. Res. 2008, 9, 132-137. 
24. Nachamkin, I. Campylobacter and Arcobacter. In Manual of Clinical Microbiology; Murray, P.R., Baron, E.J., Jorgensen, J.H., Pfaller, M.A., Yolken, R.H., Eds.; American Society for Microbiology: Washington, DC, USA, 2003; pp. 902-914.

25. Hoshino, K.; Yamasaki, S.; Mukhopadhyay, A.K.; Chakraborty, S.; Basu, A.; Bhattacharya, S.K.; Nair, G.B.; Shimada, T.; Takeda, Y. Development and evaluation of a multiplex PCR assay for rapid detection of toxigenic Vibrio cholerae $\mathrm{O} 1$ and O139. FEMS Immunol. Med. Microbiol. 1998, 20, 201-207. [CrossRef]

26. Samosornsuk, W.; Asakura, M.; Yoshida, E.; Taguchi, T.; Nishimura, K.; Eampokalap, B.; Phongsisay, V.; Chaicumpa, W.; Yamasaki, S. Evaluation of a cytolethal distending toxin $(c d t)$ gene-based species-specific multiplex PCR assay for the identification of Campylobacter strains isolated from poultry in Thailand. Microbiol. Immunol. 2007, 51, 909-917. [CrossRef] [PubMed]

27. Linton, D.; Lawson, A.; Owen, R.; Stanley, J. PCR detection, identification to species level, and fingerprinting of Campylobacter jejuni and Campylobacter coli direct from diarrheic samples. J. Clin. Microbiol. 1997, 35, 2568-2572. [CrossRef] [PubMed]

28. Asakura, M.; Samosornsuk, W.; Taguchi, M.; Kobayashi, K.; Misawa, N.; Kusumoto, M.; Nishimura, K.; Matsuhisa, A.; Yamasaki, S. Comparative analysis of cytolethal distending toxin (cdt) genes among Campylobacter jejuni, C. coli and C. fetus strains. Microb. Pathog. 2007, 42, 174-183. [CrossRef] [PubMed]

29. Luangtongkum, T.; Morishita, T.Y.; El-Tayeb, A.B.; Ison, A.J.; Zhang, Q. Comparison of antimicrobial susceptibility testing of Campylobacter spp. by the agar dilution and the agar disk diffusion methods. J. Clin. Microbiol. 2007, 45, 590-594. [CrossRef] [PubMed]

30. Clinical \& Laboratory Standards Institute (CLSI). Performance Standards for Antimicrobial Susceptibility Testing, 26th ed.; CLSI Supplement M100S: Wayne, PA, USA, 2016; pp. 1-256.

31. Centers for Disease Control and Prevention (CDC). Epi Info ${ }^{\mathrm{TM}} 7$. User Guide. Available online: https: //www.cdc.gov/epiinfo/support/userguide.html (accessed on 29 September 2020).

32. Livestock Economy at a Glance 2019, 20. Department of Livestock Services, Ministry of Fisheries and Livestock, Government of the People's Republic of Bangladesh. 2020. Available online: http://dls.portal.gov.bd/sites/default/files/files/dls.portal.gov.bd/page/ee5f4621_fa3a_40ac_8bd9_ 898fb8ee4700/2020-07-22-19-34-e4cd5ed65f45419ee038e00b8939c1a0.pdf (accessed on 29 September 2020).

33. Hamid, M.; Rahman, M.; Ahmed, S.; Hossain, K. Status of poultry industry in Bangladesh and the role of private sector for its development. Asian J. Poult. Sci. 2017, 11, 1-13. [CrossRef]

34. Rahman, M.A.; Rahman, M.M.; Moonmoon, M.; Alam, K.J.; Islam, M.Z. Prevalence of common diseases of broiler and layer at Gazipur district in Bangladesh. Asian J. Med. Biol. Res. 2017, 3, 290-293. [CrossRef]

35. Malik, H.; Kumar, A.; Rajagunalan, S.; Kataria, J.; Sachan, S. Prevalence of Campylobacter jejuni and Campylobacter coli among broilers in Bareilly region. Vet. World 2014, 7. [CrossRef]

36. Nisar, M.; Mushtaq, M.H.; Shehzad, W.; Hussain, A.; Nasar, M.; Nagaraja, K.V.; Goyal, S.M. Occurrence of Campylobacter in retail meat in Lahore, Pakistan. Acta Trop. 2018, 185, 42-45. [CrossRef]

37. Hussain, I.; Mahmood, M.S.; Akhtar, M.; Khan, A. Prevalence of Campylobacter species in meat, milk and other food commodities in Pakistan. Food Microbiol. 2007, 24, 219-222. [CrossRef]

38. Kottawatta, K.S.; Van Bergen, M.A.; Abeynayake, P.; Wagenaar, J.A.; Veldman, K.T.; Kalupahana, R.S. Campylobacter in broiler chicken and broiler meat in Sri Lanka: Influence of semi-automated vs. wet market processing on Campylobacter contamination of broiler neck skin samples. Foods 2017, 6, 105. [CrossRef]

39. Stern, N.; Cox, N.; Bailey, J.; Berrang, M.; Musgrove, M. Comparison of mucosal competitive exclusion and competitive exclusion treatment to reduce Salmonella and Campylobacter spp. colonization in broiler chickens. Poult. Sci. 2001, 80, 156-160. [CrossRef] [PubMed]

40. Maćkiw, E.; Korsak, D.; Rzewuska, K.; Tomczuk, K.; Rożynek, E. Antibiotic resistance in Campylobacter jejuni and Campylobacter coli isolated from food in Poland. Food Control 2012, 23, 297-301. [CrossRef]

41. Zhu, J.; Yao, B.; Song, X.; Wang, Y.; Cui, S.; Xu, H.; Yang, B.; Huang, J.; Liu, G.; Yang, X. Prevalence and quantification of Campylobacter contamination on raw chicken carcasses for retail sale in China. Food Control 2017, 75, 196-202. [CrossRef]

42. Vindigni, S.M.; Srijan, A.; Wongstitwilairoong, B.; Marcus, R.; Meek, J.; Riley, P.L.; Mason, C. Prevalence of foodborne microorganisms in retail foods in Thailand. Foodborne Pathog. Dis. 2007, 4, 208-215. [CrossRef]

43. Huong, L.Q.; Hanh, T.T.; Cam, P.D.; Be, N.T. Study on the prevalence of Campylobacter spp. from chicken meat in Hanoi, Vietnam. Ann. N. Y. Acad. Sci. 2006, 1081, 273-275. [CrossRef] 
44. Lay, K.S.; Vuthy, Y.; Song, P.; Phol, K.; Sarthou, J.L. Prevalence, numbers and antimicrobial susceptibilities of Salmonella serovars and Campylobacter spp. in retail poultry in Phnom Penh, Cambodia. J. Vet. Med. Sci. 2011, 73, 325-329. [CrossRef]

45. Coates, D.; Hutchinson, D.; Bolton, F. Survival of thermophilic Campylobacters on fingertips and their elimination by washing and disinfection. Epidemiol. Infect. 1987, 99, 265-274. [CrossRef]

46. Griffiths, P.; Park, R. Campylobacters associated with human diarrhoeal disease. J. Appl. Bacteriol. 1990, 69, 281-301. [CrossRef]

47. United Nations Children's Emergency Fund (UNICEF). Evaluation of Avian Influenza Communication for Development Initiative -Improving Biosecurity in Live Bird Markets: Lessons Learned Report; United Nations Children's Emergency Fund (UNICEF): Dhaka, Bangladesh, 2013. Available online: https://www.unicef.org/ cbsc/files/Avian_Campaign_Eval-Bangladesh-2014.pdf (accessed on 30 September 2020).

48. Nasreen, S.; Khan, S.U.; Luby, S.P.; Gurley, E.S.; Abedin, J.; Zaman, R.U.; Sohel, B.M.; Rahman, M.; Hancock, K.; Levine, M.Z. Highly pathogenic avian influenza A (H5N1) virus infection among workers at live bird markets, Bangladesh, 2009-2010. Emerg. Infect. Dis. 2015, 21, 629-637. [CrossRef]

49. Smith, S.; Messam, L.L.M.; Meade, J.; Gibbons, J.; McGill, K.; Bolton, D.; Whyte, P. The impact of biosecurity and partial depopulation on Campylobacter prevalence in Irish broiler flocks with differing levels of hygiene and economic performance. Infect. Ecol. Epidemiol. 2016, 6, 1. [CrossRef]

50. Battersby, T.; Whyte, P.; Bolton, D. The pattern of Campylobacter contamination on broiler farms; external and internal sources. J. Appl. Microbiol. 2016, 120, 1108-1118. [CrossRef] [PubMed]

51. Newell, D.; Fearnley, C. Sources of Campylobacter colonization in broiler chickens. Appl. Environ. Microbiol. 2003, 69, 4343-4351. [CrossRef] [PubMed]

52. Ratananakorn, L.; Wilson, D. Zoning and compartmentalisation as risk mitigation measures: An example from poultry production. Rev. Sci. Tech. 2011, 30, 297-307. [CrossRef] [PubMed]

53. Mridha, D.; Uddin, M.N.; Alam, B.; Akhter, A.H.M.T.; Islam, S.S.; Islam, S.; Khan, M.S.R.; Kabir, S.M.L. Identification and characterization of Salmonella spp. from samples of broiler farms in selected districts of Bangladesh. Vet. World 2020, 13, 275-283. [CrossRef]

54. Perdoncini, G.; Sierra-Arguello, Y.M.; Lima, L.M.; Trindade, M.M.; Gomes, M.J.P.; Santos, L.R.D.; Schmidt, V.; Nascimento, V.P.D. Occurrence of Campylobacter jejuni and C. coli on broiler carcasses after chilling in southern Brazil. Pesqui. Vet. Bras. 2015, 35, 349-352. [CrossRef]

55. Zhang, T.; Luo, Q.; Chen, Y.; Li, T.; Wen, G.; Zhang, R.; Luo, L.; Lu, Q.; Ai, D.; Wang, H. Molecular epidemiology, virulence determinants and antimicrobial resistance of Campylobacter spreading in retail chicken meat in Central China. Gut Pathog. 2016, 8, 48. [CrossRef]

56. Padungtod, P.; Kaneene, J.B. Campylobacter in food animals and humans in northern Thailand. J. Food Prot. 2005, 68, 2519-2526. [CrossRef]

57. Animal Feed. Act. Department of Livestock Services, Ministry of Fisheries and Livestock, Government of the Peoples' Republic of Bangladesh. 2010; pp. 1-9. Available online: https://mofl.gov.bd/sites/default/files/ files/mofl.portal.gov.bd/law/61eacebb_edf0_483c_a09f_f9c2fa5de36b/Animal\%20Feed\%20rule-2013.pdf (accessed on 11 November 2020).

58. Singer, R.S.; Finch, R.; Wegener, H.C.; Bywater, R.; Walters, J.; Lipsitch, M. Antibiotic resistance-The interplay between antibiotic use in animals and human beings. Lancet Infect. Dis. 2003, 3, 47-51. [CrossRef]

59. Babapour, A.; Azami, L.; Fartashmehr, J. Overview of antibiotic residues in beef and mutton in Ardebil, North West of Iran. World Appl. Sci. J. 2012, 19, 1417-1422. [CrossRef]

60. Moyane, J.; Jideani, A.; Aiyegoro, O. Antibiotics usage in food-producing animals in South Africa and impact on human: Antibiotic resistance. Afr. J. Microbiol. Res. 2013, 7, 2990-2997. [CrossRef]

61. Guetiya Wadoum, R.E.; Zambou, N.F.; Anyangwe, F.F.; Njimou, J.R.; Coman, M.M.; Verdenelli, M.C.; Cecchini, C.; Silvi, S.; Orpianesi, C.; Cresci, A. Abusive use of antibiotics in poultry farming in Cameroon and the public health implications. Br. Poult. Sci. 2016, 57, 483-493. [CrossRef] [PubMed]

Publisher's Note: MDPI stays neutral with regard to jurisdictional claims in published maps and institutional affiliations. 